\title{
Neurological deterioration induced by sitting in patients after cervicothoracic posterior decompression with instrumented fusion surgery for ossification of the longitudinal ligament: two cases reports
}

\author{
Masao Koda ${ }^{1 *}$, Chikato Mannoji ${ }^{2}$, Taigo Inada ${ }^{1}$, Koshiro Kamiya ${ }^{1}$, Mitsutoshi Ota' ${ }^{1}$ Satoshi Maki ${ }^{1}$, \\ Kazuhisa Takahashi', Masashi Yamazaki ${ }^{3}$, Masaaki Aramomi', Osamu Ikeda ${ }^{1}$ and Takeo Furuya ${ }^{1}$
}

\begin{abstract}
Background: We report on Japanese patients who showed neurological deterioration induced by sitting after cervicothoracic posterior decompression with instrumented fusion, but showed immediate neurological recovery after bed rest.

Case Presentation: Patients showed incomplete paraparesis caused by the ossification of the posterior longitudinal ligament at uppermost thoracic spine. Cervicothoracic posterior decompression with instrumented fusion was performed. Postoperatively, the patients showed partial paraparesis when they were sitting. They showed rapid recovery from lower extremity paralysis upon lying down. After strict bed rest for one month, those patients showed no apparent development of paralysis during sitting.
\end{abstract}

Conclusion: In patients with postoperative residual anterior spinal cord compression, micromotion might exacerbate neurological symptoms.

Keywords: Ossification of the posterior longitudinal ligament, Posterior surgery, Instrumented fusion, Postoperative complication

\section{Background}

Ossification of the longitudinal ligament (OPLL) is one of anterior spinal cord compressive lesions at the uppermost thoracic spine, and is often treated using a posterior approach to decompression because of the anatomical complexity of the upper mediastinum [1]. OPLL patients showing local kyphosis often have a poor surgical outcome after posterior decompression surgery alone [2]. Concurrent instrumented posterior fusion is usually adopted as a stabilization procedure. The rationale for posterior decompression with instrumented fusion surgery $(\mathrm{PDF})$ is to obtain neurological recovery by

\footnotetext{
* Correspondence: masaokod@gmail.com

'Departments of Orthopedic Surgery, Chiba University Graduate School of Medicine, 1-8-1, Inohana, Chuo-K, Chiba 260-8670, Japan

Full list of author information is available at the end of the article
}

immediate stabilization of the spine, even if there is residual anterior compression following the procedure [3-6]. Here we report two cases that showed neurological deterioration induced by sitting after cervicothoracic PDF for OPLL, but showed immediate neurological recovery after bed rest.

\section{Case presentations}

Case 1

A 71-year-old Japanese woman complained of difficulty walking caused by OPLL at T2-3. C7-T5 PDF surgery was performed (Figure 1A, B, C). Three days after surgery, the patient showed partial paraparesis when she was sitting. Emergent CT and MRI showed no apparent abnormalities (Figure 1D). During those examinations, the patient gradually recovered from lower extremity paralysis. We ordered 

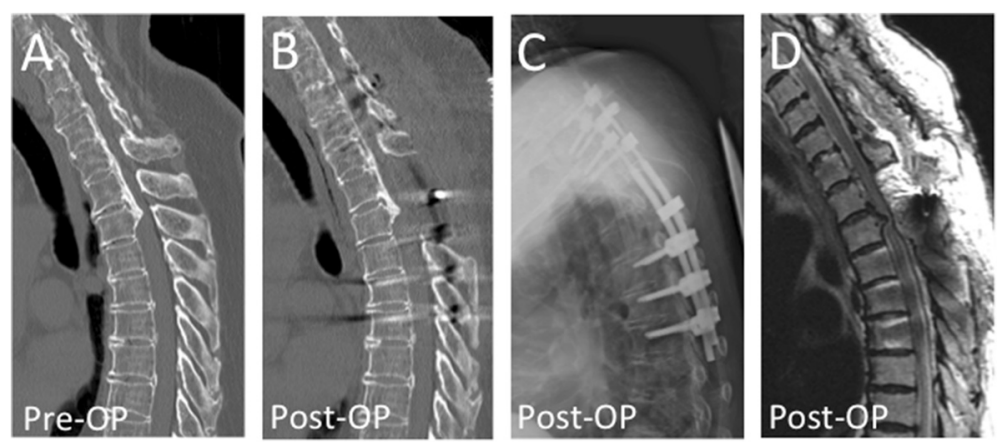

Figure 1 Pre- and postoperative images of Case 1. Pre-operative computed tomography image showed beak-shaped ossification of the posterior longitudinal ligament at T2/3 vertebral level (A). Posterior decompression with instrumented fusion surgery at C7-T5 level was performed (B-D). This patient showed partial paraparesis when she was sitting, but showed immediate neurological recovery after bed rest.

strict bed rest without sitting up for one month. Subsequently, the patient showed no apparent development of paralysis during sitting or using a wheelchair.

\section{Case 2}

A 37-year-old Japanese man showed partial paraparesis because of OPLL at C3-T3 (worst at T1-2, Figure 2A). The patient underwent PDF surgery at C3-T5. The patient showed incomplete paralysis on sitting, but rapidly recovered after bed rest. An emergent CT-myelogram revealed no apparent abnormalities (Figure 2B). X-ray images obtained when the patient was sitting and lying showed no apparent motion between fused segments (C7-T4 angle was $4^{\circ}$ in both lying and in sitting position, Figure $2 \mathrm{C}$ and $\mathrm{D})$. We ordered strict bed rest for 3 weeks. Subsequently, the patient showed no apparent development of paralysis during sitting.

\section{Discussion}

Points in common between the present patients were that there was an anterior spinal cord compressive lesion at the upper thoracic level, that there was residual anterior spinal cord compression after surgery and the cervical $3.5 \mathrm{~mm}$ diameter rods were used at the cervicothoracic region. Previous Japanese reports describing neurological deterioration induced by sitting after cervicothoracic posterior decompression with instrumented fusion for OPLL showed similarities with the present patients $[7,8]$. Both of the present cases showed rapid neurological deterioration with sitting, followed by rapid recovery on lying down. These lines of indirect evidence lead us to suggest that, even after PDF surgery, there is micromotion at the fused segments. In contrast, no mid- to lower-thoracic OPLL patients showed neurological deterioration at sitting after PDF surgery in our previous series $[5,6]$.

The possible differences between the previous midto lower-thoracic OPLL series and the present cases are the difference in the region and the difference of rod diameter, tapered rod $(4.5 \mathrm{~mm}$ thoracic and 3.5 cervical) for case 1 and $3.5 \mathrm{~mm}$ cervical rod for case 2 . Upper thoracic spinal cord might be vulnerable for external force because of its specific blood supply [9]; therefore in patients with postoperative residual anterior
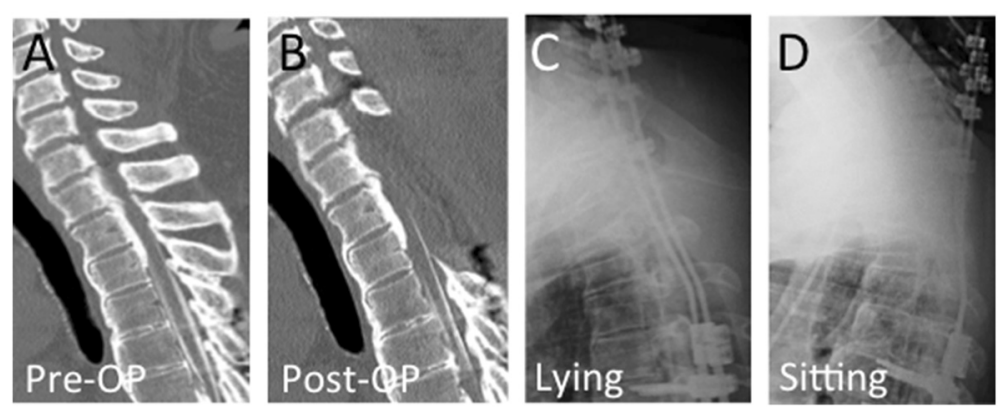

Figure 2 Pre- and postoperative images of Case 2. Pre-operative computed tomography image showed peak of ossification of the posterior longitudinal ligament at T1/2 vertebral level (A). C3-T5 posterior decompression with instrumented fusion surgery was performed. The patient showed incomplete paralysis on sitting, but rapidly recovered after bed rest. An emergent computed tomographic-myelogram revealed no apparent abnormalities (B). X-ray images obtained when the patient was lying (C) and sitting (D) showed no apparent motion between fused segments. 
spinal cord compression at upper thoracic region, the spinal cord might be more vulnerable for micromotion than in the patients of mid- to lower thoracic spinal level.

\section{Conclusion}

In conclusion, we recommend surgeons be alert to the possibility of micromotion after cervicothoracic PDF surgery for OPLL. Thicker or more rigid rods for the PDF surgery may suppress this micromotion.

\section{Consent}

Written informed consent was obtained from both of the patients for publication of this Case Report and any accompanying images. A copy of the written consent is available for review by the Editor-in-Chief of this journal.

\section{Abbreviations}

OPLL: Ossification of the posterior longitudinal ligament; PDF: Ossification of the longitudinal ligament; CT: Computed tomography; MR: Magnetic

resonance.

\section{Competing interests}

The authors declare that they have no competing interests.

\section{Authors' contributions}

$M K, C M, T I, K K, M O$ and SM analyzed and interpreted the patient data. KT, MY, MA, Ol and TF were major contributors in writing the manuscript. All authors read and approved the final manuscript.

\section{Acknowledgement}

There is no source of funding for all authors.

\section{Author details}

${ }^{1}$ Departments of Orthopedic Surgery, Chiba University Graduate School of Medicine, 1-8-1, Inohana, Chuo-K, Chiba 260-8670, Japan. ${ }^{2}$ Chiba Aoba

Municipal Hospital, Chiba, Japan. ${ }^{3}$ University of Tsukuba, Tsukuba, Japan.

Received: 3 January 2015 Accepted: 31 March 2015

Published online: 09 April 2015

\section{References}

1. Miscusi M, Bellitti A, Polli FM. Surgical approaches to the cervico-thoracic junction. J Neurosurg Sci. 2005;49:49-57.

2. Yamazaki M, Okawa A, Koda M, Goto S, Minami S, Moriya H. Transient paraparesis after laminectomy for thoracic myelopathy due to ossification of the posterior longitudinal ligament: a case report. Spine. 2005;30:E343-6.

3. Matsumoto M, Chiba K, Toyama Y, Takeshita K, Seichi A, Nakamura K. Surgical results and related factors for ossification of posterior longitudinal ligament of the thoracic spine: a multi-institutional retrospective study. Spine. 2008:33:1034-41.

4. Matsumoto M, Toyama Y, Chikuda H, Takeshita K, Kato T, Shindo S, et al. Outcomes of fusion surgery for ossification of the posterior longitudinal ligament of the thoracic spine: a multicenter retrospective survey. J Neurosurg Spine. 2011;15:380-5.

5. Yamazaki M, Mochizuki M, Ikeda Y, Sodeyama T, Okawa A, Koda M, et al. Clinical results of surgery for thoracic myelopathy caused by ossification of the posterior longitudinal ligament: operative indication of posterior decompression with instrumented fusion. Spine. 2006;31:1452-60.

6. Yamazaki M, Okawa A, Fujiyoshi T, Furuya T, Koda M. Posterior decompression with instrumented fusion for thoracic myelopathy caused by ossification of the posterior longitudinal ligament. Eur Spine $J$. 2010;19:691-8.
7. Koga T. Early deterioration after posterior decompression surgery for cervico-thoracic ossification of the longitudinal ligament (in Japanese). J Japan Soc Spine Surg Rel Res. 2009;22:889-92.

8. Yamaguchi M, Nakamura E, Narusawa K, Shimizu K, Suzuki M, Matsumoto K, et al. Surgical Treatment for Thoracic OPLL: A Report of Two Cases (in Japanese). Orthop Traumatol. 2008;57:419-23.

9. Jellinger KA. Spinal cord watershed. Neurology. 1997;48:1474.

\section{Submit your next manuscript to BioMed Central and take full advantage of:}

- Convenient online submission

- Thorough peer review

- No space constraints or color figure charges

- Immediate publication on acceptance

- Inclusion in PubMed, CAS, Scopus and Google Scholar

- Research which is freely available for redistribution 